Original Research Article

\title{
Simple Determination of Average Degree Polymerization of Inulin from Dahlia Tuber Using Spectrophotometer
}

\author{
Iren Gusni Yanti ${ }^{1}$, Minda Azhar ${ }^{2}$, Anni Faridah $^{3}$, Budhi Oktavia ${ }^{2}$ \\ ${ }^{1}$ Chemistry Department, Faculty of Mathematics and Natural Sciences, Universitas Negeri Padang \\ ${ }^{2}$ Jln. Prof. Dr. Hamka, Air Tawar, Padang, Indonesia \\ ${ }^{3}$ Faculty of Tourism and Hospitality, Universitas Negeri Padang \\ Corresponding Author: Minda Azhar
}

\begin{abstract}
The degree of polymerization (DP) of inulin is the number of monomer units in inulin polymer strand. DP inulin can be determined simply using spectrophotometer. This study aims to determine DP inulin from fresh dahlia tubers and dahlia tubers that are stored for fifteen days. Inulin extraction from dahlia tuber was based on the solubility of inulin in hot water and precipitation in ethanol by adding ethanol to final concentration of $80 \%$ solution. Reducing sugars in inulin was determined using the DNS method. The absorbances were measured using spectrophotometer at maximum wavelength of 490 $\mathrm{nm}$. Total sugar of inulin was determined using Phenol-Sulfate method, the absorbance was measured at $\lambda_{\max } 350 \mathrm{~nm}$. Inulin from fresh dahlia tubers had average DP higher than inulin from dahlia tuber that stored for fifteen days. Inulin that found in this research belongs to the fructooligosaccharide (FOS) group.
\end{abstract}

Keywords: Degree polymerization (DP) of inulin, dahlia tubers, DNS, phenol-sulfate, reducing sugars, spectrophotometer genesys 20.

\section{INTRODUCTION}

Inulin is fructant group polysaccharide, which consists of the main unit $\beta-(2 \rightarrow 1)$ fructofuranosil $(\mathrm{Fm})$ and one $\alpha$-glycopiranose $(1 \rightarrow 2)$ (GFn) terminal unit. The degree of polymerization (DP) inulin varies from 2 to 70 , whereas inulin molecules with DP 2-10 are called oligofructose or fructooligosaccharides (FOSs) (Petkova \& Denev, 2015).

Natural sources of inulin include chicory roots, Jerusalem artichokes, dahlia tuber, yacon, asparagus, leeks, onions, bananas, wheat and garlic (Shoaib et al., 2016). Most commercial inulin is produced from chicory, dahlia tubers and Jerusalem artichoke because it has high inulin content.

Inulin is widely used in the food industry to modify textures, replace fat or as low-calorie sweetener. Generally, inulin is used as prebiotic for the development of functional foods to improve health. In addition, it has several applications in other fields such as pharmacy. Mostly inulin is used as diagnostic agents for kidney function and as protein stabilizer (Mensink et al., 2015; Shoaib et al., 2016).

DP inulin has effect on inulin function (Shoaib et al., 2016). Inulin with low DP is suitable to be used as prebiotic, whereas inulin with a high DP can be hydrolyzed into FOS. In this regard, the development of analytical methods for determining of DP is very important for the inulin characterization and its derivatives in plant samples (Saengkanuk et al., 2011). Some simple methods for determining of DP are fast, specific and suitable for 
analysis including spectrophotometry, and chromatographic methods (Petkova and Denev, 2015).

The inulin DP is influenced by several factors, such as plant sources, climate and growth conditions, maturity of the harvest and storage time after harvest (Chi et al., 2011). In this study, inulin DP was determined from fresh dahlia tubers and dahlia tubers which are stored for fifteen days.

\section{RESEARCH METHODS \\ Time and Place}

This research was done at the Chemistry Laboratory, Faculty of Mathematics and Natural Sciences, Universitas Negeri Padang from February to July 2019.

\section{Tools and Materials}

Tools

The tools used in the research carried out were blender, sifter $850 \mu \mathrm{m}$, glassware, refrigerator, technical balance and analytical balance, centrifugation, filter cloths, oven, thermometer, micro pipettes, micro tubes, water bath, spectrophotometer genesys 20.

Materials

Ingredients needed in the study were dahlia tubers, citric acid $0.5 \%$, ethanol, aquades, DNS reagents, fructose standard solution, phenol 5\%, and $\mathrm{H}_{2} \mathrm{SO}_{4}$ p.a. Substances used p.a.

\section{Research Procedure}

\section{Inulin Extraction from Dahlia Tubers}

Inulin extraction from fresh dahlia tubers and dahlia tubers stored for fifteen days was carried out according to the procedure K. Khuenpet et al. (2016) and Bang-orn Srinameb et al. (2015) which was slightly modified. Dahlia tubersware washed clean, cut in half, one piece was stored for fifteen days and the other piece was skinned, cut into small pieces. Pieces of dahlia tubersware immersed in citric acid $0.5 \%$ for 5 minutes, then heated in water bath $75^{\circ} \mathrm{C}$ for 2 minutes. The slice was cooled and then dried in oven at $55^{\circ} \mathrm{C}$ for 7 hours. The dried pieces ware mashed and then sieved using sieve $850 \mu \mathrm{m}$.

Inulin from dahlia tuber was extracted in hot water at $70^{\circ} \mathrm{C}$ for 30 minutes with a water: flour ratio of 10:1. The extract was filtered while warm with cloth filter. The filtrate was added with ethanol to final concentration of $80 \%$ solution, then stored in the refrigerator at $2^{\circ} \mathrm{C}$ for 19 hours, then allowed to stand at room temperature for 2 hours, then centrifuged at $5000 \mathrm{rpm}$ for 15 minutes at $4^{\circ} \mathrm{C}$ to obtain a precipitate and supernatant. The precipitate was dried in oven at $40^{\circ} \mathrm{C}$. Fructose Standard Curve of DNS Method

DNS reagents were made according to the procedure of Coughlan \& Moloney (1988). Standard fructose solution was made with a concentration of $200-600 \mu \mathrm{g} / \mathrm{mL}$. Each fructose solution was pipetted $75 \mu \mathrm{L}$ into a micro tube, then added $75 \mu \mathrm{L}$ of DNS reagent. The solution was heated in boiling water for 10 minutes, cooled at room temperature, added $850 \mu \mathrm{L}$ distilled water and homogenized. Absorption was measured at $\lambda 490 \mathrm{~nm}$.

Preparation of the Standard Curve of the Phenol-Sulfate Method

Concentrations of fructose standard solution were 200-800 $\mu \mathrm{g} / \mathrm{mL}$. Each fructose solution was pipetted $1 \mathrm{~mL}$ into a test tube, then added $0.5 \mathrm{~mL}$ of phenol $5 \%$, shaken, then added $2.5 \mathrm{~mL}$ of $\mathrm{H}_{2} \mathrm{SO}_{4}$ p.a by pouring perpendicularly to the surface of the solution quickly. The solution was left for 10 minutes, then shaken. The solution was placed in a water bath for 15 minutes, then cooled at room temperature, then added 8 $\mathrm{mL}$ of distilled water, and homogenized. Absorption was measured at $\lambda 350 \mathrm{~nm}$.

Determination of Reducing Sugar

Inulin $1 \%$ pipetted $75 \mu \mathrm{L}$ into a micro tube, then added $75 \mu \mathrm{L}$ DNS reagent. The solution is placed in a boiling water bath for 10 minutes, and cooled at room temperature. The solution is diluted with distilled water and homogenized. Absorption was measured at $\lambda 490 \mathrm{~nm}$. Determination of Total Sugar 
Inulin $1 \%$ was pipetted $1 \mathrm{~mL}$ into the test tube, then added $0.5 \mathrm{~mL}$ of phenol $5 \%$, shaken, then added $2.5 \mathrm{~mL} \mathrm{H}_{2} \mathrm{SO}_{4}$ p.a by pouring perpendicularly to the surface of the solution quickly, allowed to stand for 10 minutes, then shaken. The solution was placed in a water bath for 15 minutes, then cooled to room temperature. The solution was diluted with distilled water and homogenized. Absorption was measured at $\lambda 350 \mathrm{~nm}$.

\section{Calculation of the Inulin DP}

Average of inulin DP was calculated based on the total sugar content per reducing sugar content (Saengkanuk et al., 2011).

\section{RESULTS AND DISCUSSION Inulin Extraction from Dahlia Tubers}

Inulin extraction from dahlia tubers is based on the solubility of inulin in hot water and precipitation with ethanol at low temperatures. Dahlia tuberswere washed, skinned and cut into small pieces to speed up the drying process. The process of soaking tubers in citric acid $0.5 \%$ aims to prevent browning reactions in the tubers. The browning process in fruit that occurs due to enzymatic processes. The drying process aims to reduce the water content in the tubers. The milling and sifting process is carried out in order to obtain finer root flour so as to facilitate the inulin extraction process.

Inulin from dahlia tuber was extracted in hot water at $70^{\circ} \mathrm{C}$ for 30 minutes to dissolve the inulin in the dahlia tuber. The process based on the solubility of inulin in hot water. Temperature above $135^{\circ} \mathrm{C}$ will damaged inulin structure. The inulin filtrate in cold ethanol $80 \%$ was centrifuged at $5000 \mathrm{rpm}$ for 15 minutes, $4^{\circ} \mathrm{C}$ to separate the inulin and supernatant deposits. The precipitate was dried to obtain dry inulin. Inulin that obtained from dry weight dahlia tuber of fresh tuber was $22.2 \%$ while inulin of dahlia tuber from fifteen days storage was $23.3 \%$. This difference is caused by decrease in water content during the storage time.

\section{Fructose Standard Curve of the DNS Method}

Absorbance of standard solutions was measured at a concentration of 200 to $600 \mu \mathrm{g} / \mathrm{mL}$ at $\lambda 490 \mathrm{~nm}$. The regression equation obtained is $\mathrm{y}=0.0018 \mathrm{x}+0.1608$ with an $\mathrm{R}^{2}$ value of 0.9917 . This value showed that the absorbance at each concentration of fructose solution is very close to a straight line. The relationship curve between fructose concentration and its absorbance was shown in Figure 1.

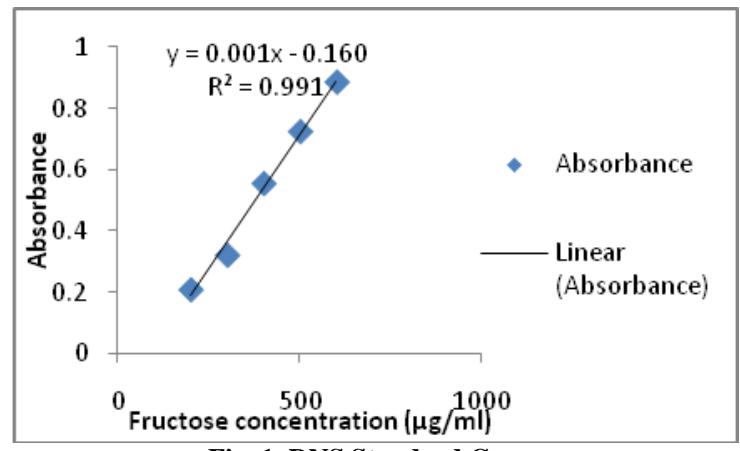

Fig. 1. DNS Standard Curve

The linear regression equation of the standard fructose solution obtained from the DNS standard curve was used to determine the reducing sugar in inulin.

The Standard Fructose Curve of the PhenolSulfate Method

Absorbance of standard fructose solutions was measured at a concentration of 200 to $800 \mu \mathrm{g} / \mathrm{mL}$ at $\lambda 350 \mathrm{~nm}$. The regression equation obtained is $\mathrm{y}=0.0011 \mathrm{x}+0.0736$ with an $\mathrm{R}^{2}$ value of 0.9904 . This value shows that the absorbance at each concentration of fructose solution is very close to a straight line. The relationship curve between fructose concentration and its absorbance was shown in Figure 2.

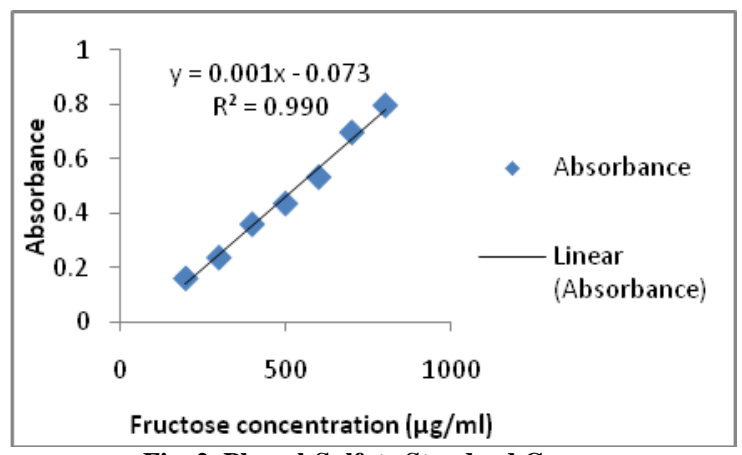

Fig. 2. Phenol-Sulfate Standard Curve. 
The linear regression equation of the standard fructose solution obtained from the standard phenol-sulfate curve is used to determine the total sugar in inulin.

\section{Reducing Sugar Contents}

The characteristic of reducing sugars is the ability to reduce them in an alkaline state. All monosaccharides are included in the reducing sugar group. Disaccharides which include reducing sugars are maltose, lactose, and isomaltose. The sugar has reducing properties because sugar molecule had ketones or aldehydes group (Goutara and Widjandi, 1975).

Reducing sugars in inulin was determined using dinitrosalilatilat (DNS) method. The value of reducing sugar of inulin obtained in fresh tubers was 8.020 $\mu \mathrm{g} / \mathrm{mL}$, while the value of reducing sugar obtained in stored dahlia tubers for fifteen days was $8.264,44 \mu \mathrm{g} / \mathrm{mL}$.

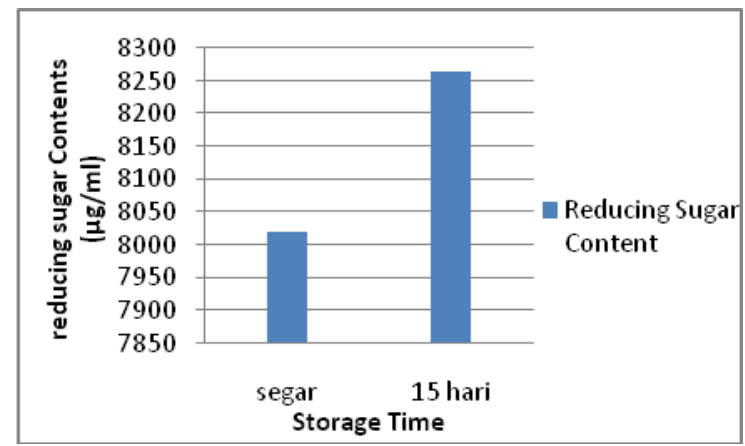

Fig. 3. Diagram of the relationship between reducing sugar value and storage time of dahlia tubers.

Value of inulin reducing sugars in the dahlia tubers increase with storage time. Value of inulin reducing sugars in stored dahlia tubers for fifteen days was greater than inulin in fresh dahlia tubers. Dahlia tuber contained inulinase. The enzyme can catalysis hydrolysis reaction of inulin to form fructooligosaccharides (FOS) through endo-inulinase activity, and become fructose monomers through exo-inulinase activity. Exo-inulinase can produce fructose by cutting the $\beta-2.1$ bond of inulin molecule (Magunwidjaja et al., 2014). The more inulin that hydrolyzed, the more fructose and FOS are formed so that the greater the amount of reducing sugar produced.

\section{Total Sugar Contents}

Total sugar or also called total carbohydrate according to Apriyantono et al (1986) is the sum of all simple sugars, oligosaccharides, polysaccharides and their derivatives. Analysis to determine the total sugar is done by the phenol method. The sample was reacted with phenol in $\mathrm{H}_{2} \mathrm{SO}_{4}$ p.a to produce a stable orange-yellowish color. Total sugar content was calculated from absorbance values obtained based on the phenol standard curve equation (Figure 2 ), so that the total sugar content in fresh samples was $41.780 \mu \mathrm{g} / \mathrm{mL}$ and the total sugar content in fifteen days stored samples was $21.451,81 \mu \mathrm{g} / \mathrm{mL}$.

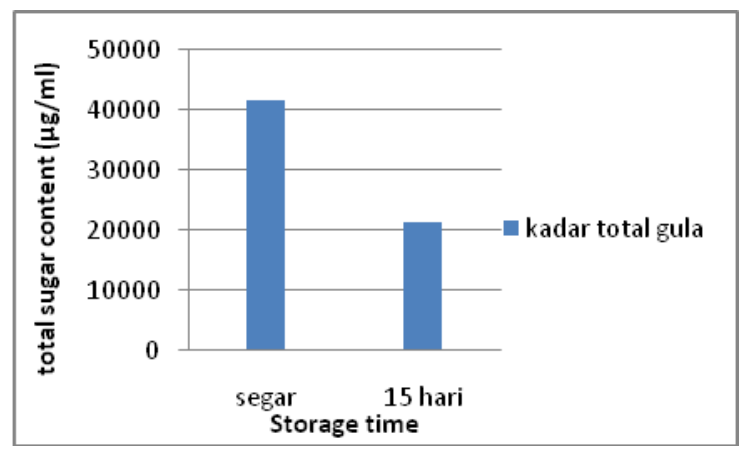

Fig. 4. Diagram of the relationship between total sugar value and storage time of dahlia tubers.

The total sugar contained in inulin from fresh dahlia tubers is higher than the total sugar contained in inulin from dahlia tubers stored for fifteen days. Total sugar was determined based on complete hydrolysis of inulin using acids. Product of the complete hydrolysis was fructoses and glucoses. Process hydrolysis of inulin that had high DP produce more fructose monomers, so its high total sugar. Total sugar was determined for determination of inulin DP in dahlia tubers.

\section{Degree Polymerization of Inulin}

Inulin DP is the number of monomer units in an inulin polymer strand. DP of inulin depends on many factors, such as plant sources, climate and growth conditions, maturity of the harvest and storage time after harvest (Chi et al., 2011). 


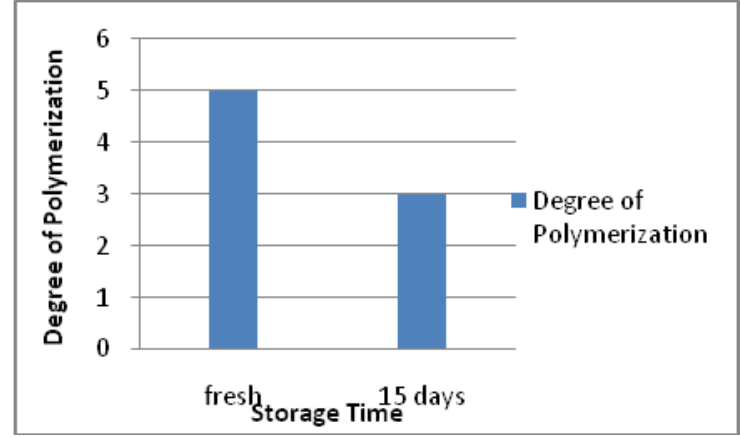

Fig. 5. Diagram of the relationship between the degree of polymerization and the storage time of the dahlia tubers

The storage time has effect on inulin DP of dahlia tubers (fig. 5). Inulin DP from fresh dahlia tubers higher than inulin DPin stored dahlia tubers fifteen days. Dahlia tuber contained inulinase. DP inulin from freshly extracted dahlia tubers is greater than dahlias which are stored for 4 weeks (Hevi, et al., 2017). The same thing in the artichoke storage period accompanied a decrease in average inulin and DP levels, which was caused by depolymerization of high molecular weight carbohydrate molecules (Chi et al., 2011). DP inulin in Jerussalem artichoke tubers changes during storage after harvest. DP fraction 3-10 increased and the DP fraction $>10$ decreased after 4-6 weeks of storage of Jerussalem artichoke tubers (Helianthus tuberosus L) (Saengthongpinit, 2005).

Inulinase is an enzyme that is able to hydrolyze inulin to form fructooligosaccharides (FOS) through endo-inulinase activity, and become fructose monomers through exo-inulinase activity. Exoinulinase can produce fructose by cutting the $\beta-2.1$ bond in sequence. Endo-inulinase can produce FOS by randomly cutting and hydrolyzing the internal bonds in inulin (Magunwidjaja et al., 2014). The more inulin that is hydrolyzed, the more fructose and FOS are formed so that the lower DP is produced. DP inulin contained in fresh dahlia tubers was on average 5 (fructosylnystose), whereas DP inulin on dahlia tubers stored for fifteen days was on average 3 (kestose). Inulin extracted from stored dahlia tubers causes DP to be smaller.

The inulin DP from dahlia tubers is quite low, including the FOS group. This is also possible because the extracted sample of tubers is still young. DP has an effect on inulin function (Shoaib et al., 2016). Inulin with low DP is suitable for alcoholic fermentation, or for FOS production. FOS is commonly used as a substitute sweetener for sucrose in products such as cakes, bread, sweets, milk products, and some drinks because it is low in calories.

\section{CONCLUSION}

Based on the results of the study it can be concluded that DP inulin from freshly extracted dahlia tubers has an average DP higher than inulin from tubers extracted after fifteen days.

\section{ACKNOWLEDGMENT}

This research was funded by DIPA Univrsitas Negeri Padang with contract number 935/UN35.13/LT/2019.

\section{REFERENCES}

- Apriyantono, A., D.Fardiaz, N.L. Puspitasari, Sedarnawati and S.Budiyanto. 1988. Food Analysis. Bogor Agricultural University (IPB Press), Bogor.

- Chi, Z. M. Z. M., Zhang, T., Cao, T. S., Liu, X. Y., Cui, W., \& Zhao, C. H. 2011. Biotechnological potential of inulin for bioprocesses. Bioresource Technology. Elsevier Ltd, 102 (6), pp. 4295-4303.

- Horiza, H., Azhar, M., \& Efendi, J .. 2017. Extraction and Characterization of Inulin from Dahlia Tubers (Dahlia sp.L) Fresh and Stored. Eksakta UNP. Vol. 18 no.1.

- Khuenpet, K., Jittanit, W., Sirisansaneeyakul, S., \& Srichamnong, W., 2016. Inulin Powder Production from Jerusalem Artichoke (Helianthus tuberosus L.) Tuber Powder and Its Application to Commercial Food Products. Journal of ISSN Food Processing and Preservation 17454549.

- Mangunwidjadja, Djumali, Mulyorini Rahayuningsih, and Reni Suparwati. 2014. Effect of Enzymatic Concentration and Enzymatic Hydrolysis Time on the Quality of Fructo-oligosaccharides from Inulin Dahlia Tubers (Dahlia pinnata). Bogor: IPB, Vol: 3 No.1.

- Mensink, M. A. Frijlink, H. W., Van Der Voort Maarschalk, K., \& Hinrichs, W. L. J. 
2015. Inulin, a flexible oligosaccharide I: Review of its physicochemical characteristics. Carbohydrate Polymers. Elsevier Ltd., 130, pp. 405-419.

- Petkova, N., \& Denev, P. 2015. Methods for Determination of Inulin. Monograph of $4 r d$ European Young Engineers Conference 2015, (ISSN 2367-6213), 135-140.

- Saengthongpinit, W., Sajjaanantakul. 2005. Influence of Harvest Time and Temperature on Characteristics of Inulin from Jerusalem artichoke (Helianthus tuberosus L.) Tubers. Postharvest Biology and Technology. Volume 37: 93-100.

- Shoaib, M., Shehzad, A., Omar, M., Rakha, A., Raza, H., Sharif, H. R., Niazi, S. 2016. Inulin: Properties, health benefits and food applications. Carbohydrate Polymers, 147, 444-454.

- Srinameb, B., Nuchadomrong, S., Jogloy, S., Patanothai, A., Srijaranai, S., 2015. Preparation of Inulin Powder from Jerusalem Artichoke (Helianthus tuberosus L.) Tuber. Plant Food Hum Nutr. Spinger Science + Business Media New York. Published online: March 252015.

- Wijandi, S and Goutara. 1975. Basic Sugar Processing I. Department of Agricultural Product Technology - FATEMETA IPB. Bogor.

How to cite this article: Yanti IG, Azhar M, Faridah A et.al. Simple determination of average degree polymerization of inulin from dahlia tuber using spectrophotometer. International Journal of Research and Review. 2019; 6(8):399-404. 